good, describing in particular methods of calculation and giving an idea of the reliability of the displayed information.

Some minor criticisms may be made. Are large format maps really needed for some of the data, for example the one showing the isostatically adjusted bedrock? Folio presentation is luxurious and therefore expensive. I would have welcomed some additional data (for example in situ temperatures) to obtain a complete coverage of physical parameters. To balance these points the work includes vey useful and new information, for example the coastline compilation, calculated area of Antarctica, integrated subglacial and surface features, ice sheet volume and internal structure, making it a very significant and original contribution. There are still a few more sheets to be published in the coming months; data on surface temperature and accumulation, ice sheet dynamics and geological units will doubtless add considerable value to the folio. We must therefore congratulate the Scott Polar Research Institute and the editor for presenting this up-to-date compilation of physical information about Antarctica in an integrated and attractive form. This folio will certainly be useful for many research topics concerning the still poorly-known ice-sheet and continent, and will stand as a major contribution in the field for many years.

C. Lorius

Laboratoire de Glaciologie et Geophysique de l'Environnnement

Centre National de la Recherche Scientifique

38031 Grenoble CEDEX, France.

\title{
ECOLOGY OF THE TREE-LINE
}

TREE-LINE ECOLOGY: PROCEEDINGS OF THE NORTHERN QUEBEC TREE-LINE CONFERENCE. Morisset, P. and Payette, S. (editors). 1983. Québec, Centre d'études nordiques, Université Laval (Collection Nordicana, 47). 188 p, soft cover. ISBN 2.920197.47.9. Can\$15.00.

This publication presents eighteen papers by contributers from Canada, Finland, Norway, Sweden, United Kingdom and United States, given at the Second International Tree-Line Conference, held near Ungava Bay, northern Québec in mid 1981. The first conference was in Kevo, Finland, in 1977. The volume is dedicated to the memory of Professor Ilmari Hustich (1911-82) who was guest of honour of the conference and whose pioneer polar forest-line research is described by one of his colleagues in the opening paper. Following papers concern tree-line ecology particularly in Québec, Northwest Territories of Canada and northern Scandinavia, with some reference to other locations. Effects of climatic fluctuations, notably comparatively rapid colonization of alpine areas by certain tree species following warm periods of several years, are discussed with examples drawn from several regions. Holocene and recent shifts of the tree-line, and role of history in determining vegetation composition are also discussed. The final paper, by Professor Ilmari Hustich, gives most interesting subjective observations from fifty years of tree-line studies and provides a clear concept of time factors involved in substantial changes.

The papers embrace a wide range of related subjects including seed endurance, effects of fires, entomology of the tree-line area, dendrochronology and palaeoecology, geomorphological relationships and other topics. Respiration (carbon dioxide flux) and energetics of a community of Mountain Birch in northern Sweden are described, with 
details of techniques involved in the experiments. The publication is well illustrated with abundant maps, plates, and diagrams.

R. K. Headland

Scott Polar Research Institute

Lensfield Road, Cambridge CB2 IER

\section{PLANNING POLAR EXPEDITIONS}

POLAR EXPEDITIONS. Renner, G. (editor). 1984. London, Expedition Advisory Centre. 183 p, illustrated, softback. ISBN 0.907649.16.5. £5.00.

EXPEDITION PLANNERS' HANDBOOK AND DIRECTORY 1983/4. Winser, S. and Winser, N. 1984. London, Expedition Advisory Centre. 314 p, illustrated, softback. ISBN 0.907649.10.6. £6.00.

Polar Expeditions was prepared for an Expedition Advisory Centre (EAC) seminar held in March 1984 and run by the editor of the handbook, Geoff Renner. The contributors form an experienced group of polar travellers. The editor does not envisage the handbook as the final word on high latitude travel but rather as the starting block for the embryonic polar expedition. The advice offered by the experts can be broadly divided into two classes; surviving and achieving expedition objectives. In the former category problems of route-finding by map and satellite photographs, radio communications, medicine and dentistry, windchill, food and eating, safety and power supplies are tackled in the context of cold climes. It was particularly pleasing to see a section on the removal of glacial flour from drinking water, a problem that might not even be imagined by the newcomer to glacial terrains. Experience is recounted in manhaul sledging, surveying, photography and biological, glaciological and meteorological projects, all likely expedition objectives. There is a section on leading young people in the Arctic, complemented by the experiences of one of these young people. The handbook concludes with an example of the planning schedule of a model expedition (and as a member of that expedition I can guarantee its good organisation) and some information on the two major British institutions whence further advice on polar matters can be sought.

All the articles are light-heartedly written and humourously illustrated, turning the potentially gruelling task of reading a handbook into an engrossing occupation. My congratulations to the editor and contributors for achieving this. I do feel, however, that there is a slight imbalance in the space allocated to each subject. Safety, and particularly advice on river and meltstream crossing, is neglected, while photography is rather over-emphasised. Polar Expeditions is certainly worth $£ 5.00$ of precious expedition funds. However, it does not contain general information on expedition tactics such as how to carry out the initial research, fund raising, the procurement of equipment, packing and freighting, insurance etc and directories of addresses associated with each of these topics. A further outlay of $£ 6.00$ is required to gain this information from Expedition Planners Handbook and Directory 1983/4, also published by the EAC. This' is a mine of information, to which Polar Expeditions should really be regarded as a supplement for potential polar travellers. I was delighted to note that production costs on both have been kept down to allow annually updating, an essential feature of any good handbook.

Pat Langhorne

Department of Engineering

University of Cambridge 